\title{
Building scientific knowledge based on the solution of clinical cases: A contemporary learning process
}

\author{
EM Marques, FC Munhoz, ER Cunha
}

ITPAC, Instituto Tocantinense Presidente Antônio Carlos, Porto Nacional, TO

Received: 03 Sep 2021; Received in revised form: 27 Sep 2021; Accepted: 05 Oct 2021

(C2021 The Author(s). Published by TheShillonga. This is an open access article under the CC BY license

(https://creativecommons.org/licenses/by/4.0/)

\begin{abstract}
The construction of scientific knowledge based on the solution of clinical cases, also called problem-situation or case study, is a contemporary methodology, centered on the student, problematizing, teaching-learning, which allows to know the previous knowledge of the group in the face of the presented situation, as well as identifying learning needs, building new meanings and knowledge, in addition to developing specific skills for self-learning. Strategically, it is the insertion, during a course, of a social material (texts, audios, printed matter, videos), whose analysis and discussion allow to contextualize the theoretical content. This work aims to present an experience in the construction, application and evaluation of clinical cases aimed at students in the fifth period of the dentistry course at Itpac - Porto Nacional in 2020. Clinical cases were previously screened by the teacher of endodontics at the multidisciplinar clinic at Itpac - Porto Nacional and presented to students in the classroom. The students were instructed to organize themselves in groups, a time of 1 hour was established for discussion of clinical cases and websites, scientific articles and books were made available to assist in solving the proposed activity. After the end of the established time, each group presented the diagnosis of each clinical situation presented. Based on this experience, it is possible to conclude that the use of clinical cases as a pedagogical practice brings students closer to the social reality and leads them to build networks of knowledge, making them active subjects in the learning process, without renouncing the depth and specificity knowledge that a dental student needs to develop.
\end{abstract}

Keywords - About five key words in alphabetical order, separated by comma.

\section{INTRODUCTION}

According to Latif, 2014, Clinical Cases are real or fictitious situations, with summarized data and cognitive intentionality, whose objective is to introduce or illustrate certain knowledge. However, due to their theoretical nature, they do not allow real experience, being only an artificial, partial, systematic and theoretical proposal of professional practice, sometimes presented with a caricatural tone. The insertion of a clinical case in the disciplines of the basic cycle without proper contextualization and without the proper baggage of practical experience can discourage or be little enlightening, even distorting the professional reality. On the other hand, the presentation and discussion of clinical cases in the classroom as a way of stimulating reflection are essential when the student is already inserted in professional practice, in the case of Dentistry courses, or in the experience of multidisciplinary clinics, as the knowledge of the practical reality, even initial, allows a critical posture of the student in the face of the presented situation, being truly problematizing (Weeks et al., 2012).

The Motivating Case methodology, by promoting the mobilization of common sense, allows to know and challenge the previous knowledge of the group of students in the face of the presented situation, as well as to identify learning needs, to build new meanings and knowledge, in addition to developing specific skills for the student. independent study (Crowe, et al., 2011). It differs from the discussion of the Clinical Case in that the situation presented challenges the student's knowledge based on what he already brings with him knowledge of life. Even without knowing the theoretical content, the student understands the situation presented and assumes the possibility of resolution. After the presentation of the proposal, the group discussion follows, which presents the various perspectives and opinions involved, many of them contradictory or partial, making the student aware that his 
current knowledge is insufficient for a resolutive or uniform understanding. There follows an active search for knowledge and theoretical content, always under the guidance of the teacher, through the planning and execution of a strategy by the group, which generates new discussions and expansion of the perspective of the problem, seeking conciliatory syntheses (Souza et al., 2014).

\section{METHODOLOGY}

Clinical cases were previously screened by the professor of endodontics at the multidisciplinary clinic at Itpac - Porto Nacional and presented to students in the classroom. The students were instructed to organize themselves in groups, a time of 1 hour was established for the discussion of clinical cases and websites, scientific articles and books were made available to assist in solving the proposed activity. After the end of the established time, each group presented the diagnosis of each clinical situation presented (Pictures 01 and 02).
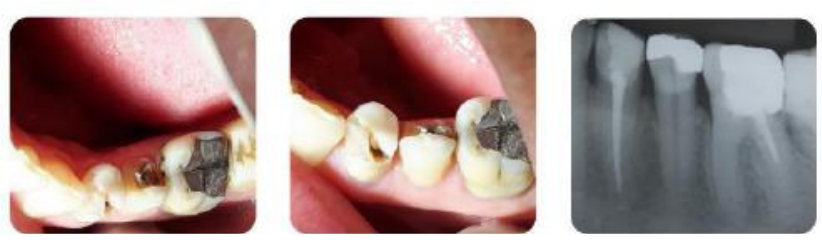

Picture 01: Clinical case 01
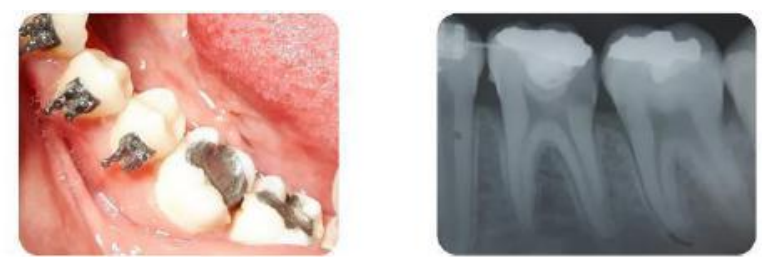

Picture 02: Clinical case 02

\section{RESULT}

Problem-solving pedagogical approaches favor the training of professionals with ethical, political and technical skills, endowed with knowledge, reasoning, criticism, responsibility and sensitivity to issues of life and society, enabling them to intervene in contexts of uncertainty and complexities. In this way, motivating cases are part of the problematizing strategy in higher education in the health area. It was found that the experience of students with clinical cases motivated the search for knowledge and learning in a more understandable teaching-learning process.

\section{CONCLUSION}

Based on this experience, it is possible to conclude that the use of clinical cases as a pedagogical practice brings students closer to the social reality and leads them to build networks of knowledge, making them active subjects of the learning process, without renouncing depth and specificity. knowledge that a dentistry student needs to develop.

\section{ACKNOWLEDGEMENTS}

An acknowledgement section may be presented after the conclusion, if desired.

\section{REFERENCES}

[1] Crowe S, Cresswell K, Robertson A, Huby G, Avery A, Sheikh A. The case study approach. BMC Medical Research Methodology 2011; 11:100-109.

[2] Latif R. Impacto of case-based lectures on students' performance in vascular physiology module.Advances in Physiology Education 2014;38:268-272.

[3] Souza CS, Iglesias AG, Pazin-Filho A. Estratégias inovadoras para métodos de ensino tradicionais - aspectos gerais. Medicina 2014;47(3):284-292.

[4] Weeks JCet al. Patients' Expectations about Effects of Chemotherapy for Advanced Cancer. The N Engl J Med 2012; 367:1616-1625. 